\title{
Prescribe Limited Quantity
}

National Cancer Institute

\section{Source}

National Cancer Institute. Prescribe Limited Quantity. NCI Thesaurus. Code C135015.

The prescriber must prescribe only a limited quantity of the drug. 